University of Wollongong

Research Online

Faculty of Engineering and Information

Faculty of Engineering and Information

Sciences - Papers: Part A

Sciences

$1-1-2015$

\title{
Validating the rejection of trace organic chemicals by reverse osmosis membranes using a pilot-scale system
}

Takahiro Fujioka

University of Wollongong, takahiro@uow.edu.au

Stuart Khan

University of New South Wales, s.khan@unsw.edu.au

James McDonald

University of New South Wales

Long D. Nghiem

University of Wollongong, longn@uow.edu.au

Follow this and additional works at: https://ro.uow.edu.au/eispapers

Part of the Engineering Commons, and the Science and Technology Studies Commons

Research Online is the open access institutional repository for the University of Wollongong. For further information contact the UOW Library: research-pubs@uow.edu.au 


\title{
Validating the rejection of trace organic chemicals by reverse osmosis membranes using a pilot-scale system
}

\begin{abstract}
A protocol to validate the rejection of organic chemicals of potential health risk by low pressure reverse osmosis (LPRO) membranes was developed for decision making support regarding the monitoring level required for potable water reuse. Ten organic chemicals were selected for evaluation, based on their recorded usage, the scarcity of rejection data, and difficulty in analytical determination at concentrations relevant to their potential impact on human-health. An analytical method was developed for these organic chemicals. The target rejections of 90 and $99 \%$ for neutral and charged chemicals respectively were successfully achieved under the standard operating condition with only two exceptions (i.e. bisoprolol and carazolol rejections by the TFC-HR membrane). These lower rejections by the TFC-HR can be attributed to its highestwater permeability amongst the three membranes while both bisoprolol and carazolol are positively charged. Changes in operating conditions including permeate flux, feed temperature and chemical cleaning can exert a considerable impact on conductivity rejection by the three LPRO membranes investigated here. Feed temperature showed an apparent impact on the rejection of the selected organic chemicals. However, their rejections were still higher than the target validation values. The protocol developed here can be expanded for the validation of other organic chemicals.
\end{abstract}

\section{Keywords}

trace organic chemicals (TrOCs), low pressure reverse osmosis, rejection validation, operating conditions, potable water reuse

Disciplines

Engineering | Science and Technology Studies

\section{Publication Details}

Fujioka, T., Khan, S. J., McDonald, J. A. \& Nghiem, L. D. (2015). Validating the rejection of trace organic chemicals by reverse osmosis membranes using a pilot-scale system. Desalination, 358 18-26. 


\section{Validating the rejection of trace organic chemicals by reverse osmosis membranes using a pilot-scale system}

Desalination

November 2014

$7 \quad \begin{array}{ll}1 & \text { Strategic Water Infrastructure Laboratory, School of Civil Mining and Environmental }\end{array}$

${ }^{2}$ UNSW Water Research Centre, School of Civil and Environmental Engineering, The University of New South Wales, NSW 2052, Australia 


\section{Abstract}

14 A protocol to validate the rejection of organic chemicals of potential health risk by low 15 pressure reverse osmosis (LPRO) membranes was developed for decision making support regarding the monitoring level required for potable water reuse. Ten organic chemicals were selected for evaluation, based on their recorded usage, the scarcity of rejection data, and difficulty in analytical determination at concentrations relevant to their potential impact on

19 human-health. An analytical method was developed for these organic chemicals. The target

20 validations of 90 and $99 \%$ for neutral and charged chemicals respectively were successfully 21 achieved under the standard operating condition with the exception of bisoprolol and carazolol rejection by the TFC-HR membrane. These lower rejections by the TFC-HR can be attributed to its highest water permeability amongst the three membranes while both bisoprolol and carazolol are positively charged. Changes in operating conditions including permeate flux, feed temperature and chemical cleaning can exert a considerable impact on conductivity rejection by the three LPRO membranes investigated here. Feed temperature showed an apparent impact on the rejection of the selected organic chemicals. However, their rejections were still higher than the target validation values. The protocol developed here can be expanded for the validation of other organic chemicals.

30 Keywords: trace organic chemicals (TrOCs); low pressure reverse osmosis; rejection validation; operating conditions; potable water reuse. 


\section{Introduction}

33 The widespread occurrence of thousands of trace organic chemicals (TrOCs) of both natural

34 and industrial origins in wastewater impacted water bodies is an important environmental issue of our time [1]. Some of these chemicals pose toxicological threats to wildlife as well as potential adverse human health effects. These TrOCs are present in reclaimed water at concentrations in the range from less than one part-per-trillion $(\mathrm{ng} / \mathrm{L})$ to a few part-per-billion $(\mu \mathrm{g} / \mathrm{L})$. Thus, they can only be detectable by some of the most advanced analytical techniques. The difficulties associated with their analysis and accurately evaluating their impact on human health present a major scientific challenge in addressing water quality problems caused by these TrOCs. One notable example is the uncertainty related to the removal of these chemicals by advanced water treatment processes, which could severely hinder the development of potable water reuse projects.

Concerns over possible adverse health impacts due to chronic and acute exposure to TrOCs via potable water recycling trigger the need to monitor their concentrations in the product water or to ascertain their removal efficiency. Routine monitoring is essential when there is a sufficient probability that certain TrOCs may occur in the product water at the threshold concentration which may result in adverse health impact. On the other hand, TrOCs (e.g. obsolete herbicides, industrial chemicals, and therapeutic drugs used in large quantity in the hospital) often do not occur in municipal wastewater or only occur at below the detection limits of most advanced analytical techniques. Thus their fates during water reclamation are largely unknown. To minimise the risk of accidental release of these TrOCs into the recycled water, a multiple barrier approach including the source water control and advanced water treatment processes has been employed in many indirect potable water reuse schemes [2].

The low pressure reverse osmosis (LPRO) filtration process is an important treatment component of many recent potable water recycling schemes. LPRO membranes are expected to effectively remove a range of TrOCs. However, to date, only a small fraction of TrOCs has been evaluated for their rejection by LPRO membranes [3-7]. Recent research in this area has resulted in a qualitative framework for assessing the removal of TrOCs by LPRO membranes.

60 As a notable example, Bellona et al., (2004) [8] developed a rejection diagram to predict the rejection of TrOCs of known physiochemical properties. Bellona's rejection diagram is based 
on the premise that the rejection of TrOCs by polyamide (PA) -based reverse osmosis (RO) membranes is mainly governed by size exclusion [8] and to a lesser extent by electrostatic interaction if the compound carries a charge. The measured rejections of most TrOCs that occur frequently in municipal wastewater at sufficiently high concentration are consistent with values estimated from this qualitative assessment framework. However, there remain many TrOCs that can potentially be introduced to municipal wastewater via uncontrolled or accidentally release but otherwise their concentrations are below the detection limits of most advanced analytical techniques. As a result, theoretical estimations of expected TrOC rejection have been suggested based on experimental results and the qualitative prediction framework by Bellona et al. [8]. Rigorous mathematic [9, 10] and artificial neural network [11] models have also been developed to predict and simulate the rejection of TrOCs by LPRO membranes under a range of operating conditions. However, the availability of these predictive tools does not replace the need to experimentally validate the rejection of TrOCs if they are not routinely monitored in potable water recycling applications.

Given the need to prioritise the monitoring efforts to manage the risk associated with TrOCs in recycled water, this study aims to identify whether the theoretical TrOC rejection based on the qualitative prediction framework by Bellona et al. [8] is valid using a spiral wound membrane system under a realistic range of filtration conditions. TrOCs were selected for this validation exercise based on an extensive literature review (to ensure that their rejections by LPRO membrane have not been previously reported in the literature) and a human health risk assessment. An analytical method was developed and optimised for the selected TrOCs. RO filtration experiments were conducted using three different LPRO membranes under a range of operating conditions (e.g. permeate flux, feed temperature and chemical cleaning). Overall, this study provides the insight of TrOC rejections by LPRO membrane for the validation of RO system performance. The validation protocol described is intended to be easily adaptable for a larger range of TrOCs selected on the basis of future membrane performance validation requirements. 


\section{Materials and methods}

90

91

92

93

94

95

96

97

98

99

100

101

102

103

104

105

106

107

108

109

110

\subsection{Chemicals}

The selection of TrOCs for this validation exercise was based on an investigation undertaken for a large Australian water utility. In total 135 TrOCs were screened based on acceptable health-based concentrations published by the Queensland Government [12], registered usage in Australia, reported occurrences in wastewater, secondary treated effluent, and RO permeate. Bellona et al. [8] conducted a comprehensive literature review to show that TrOC rejection can be qualitatively predicted based on their physicochemical properties. Based on their physicochemical properties, TrOCs can be classified into 10 categories and the rejection of each category by RO membrane can be estimated (Supplementary Material Figure S1). For each category, an assumed rejection has been determined based on conservative estimates of 0-3 Log removals of TrOCs under normal RO filtration operating conditions (Supplementary Material Table S2). The rejection categories and their assumed rejections are rough estimates based on their properties; thus, the assumed rejection values are yet to be comprehensively validated. Accordingly, a conservative validation target has been set for each category (Supplementary Material Table S2). The 10 TrOCs considered in this study have molecular weight larger than the MWCO of RO membranes and are hydrophilic at environmental $\mathrm{pH}$ (i.e. $\mathrm{pH}$ 7). Based on the qualitative prediction framework proposed here (Supplementary Material Table S2), their conservative validation targets were set at 90\% for neutral (rejection category 7 and 9) and 99\% for charged compounds (rejection category 10). Health ratio - a relationship between maximum reported TrOC concentration and their guideline limit - of selected chemical was high (0.1-1.3). All charged TrOCs selected here (Table 1) have over 99\% dissociation in $\mathrm{pH} 7.4$ solution. The $\log D$ value represents the distribution-coefficient at given $\mathrm{pH}$ indicating the hydrophobicity/hydrophilicity of a compound.

Di-n-butyl phthalate, bisoprolol, carazolol, carazolol-D7, dichloroprop, metsulfuron-methyl, molinate, penicillin $\mathrm{V}$, pirimiphos-ethyl, trichlorfon, 17 $\alpha$-estradiol, methanol, methyl-tertbutylether, ammonium acetate, and formic acid were purchased from Sigma-Aldrich (Castle Hill, NSW, Australia). Di-n-butyl phthalate-D4, carbamazepine-D10, gemfibrozil-D6 and $17 \beta$-estradiol-D4 were purchased from CDN isotopes (Pointe-Claire, Quebec, Canada). Bisoprolol-D5 and penicillin V-D5 were purchased from Toronto Research Chemicals 
119 (Toronto, Ontario, Canada). Dichloroprop-D6 and pirimiphos-ethyl-D10 were purchased 120 from Dr Ehrenstorfer GmbH (Augsburg, Germany). All chemicals were of 98.5\% purity or 121 higher. All isotope labelled standards were of at least $98 \%$ atom abundance. A stock solution 122 containing all selected TrOCs for rejection validation (Table 1) was prepared at 50-200 mg/L

123 in methanol. A stock containing the isotope labelled versions of the target compounds was 124 also prepared at $1 \mathrm{mg} / \mathrm{L}$ in methanol and used as the surrogate standard. A stock containing 125 carbamazepine-D10 was prepared at $1 \mathrm{mg} / \mathrm{L}$ in methanol and used as the internal standard 126 from compounds that did not have isotope labelled homologues. Unless otherwise stated, 127 water used for method validation samples was taken from a Milli-Q water purification system 128 (Millipore Kilsyth, Victoria, Australia).

\section{2. $R O$ feed}

131 RO feed was collected from a full-scale water recycling plant in Australia. The treatment 132 plant train prior to sampling point comprises primary treatment, bioreactor, sand filtration, 133 and microfiltration. Conductivity and $\mathrm{pH}$ of the $\mathrm{RO}$ feed were $820 \mu \mathrm{S} / \mathrm{cm}$ and 7.7, 134 respectively.

\subsection{Pilot-scale RO filtration system and RO elements}

136 A pilot-scale cross-flow RO filtration system was used. The system comprised three 4-inch 137 fibreglass pressure vessels, a high pressure pump (CRN 3-25, Grundfos, Bjerringbro, 138 Denmark) and $300 \mathrm{~L}$ polyethylene feed reservoir (Figure 1). The feed stream of the three 139 pressure vessels was connected in series. One 4 inch $\times 40$ inch LPRO membrane element was 140 held in each pressure vessel. Stainless steel pipes and PVC pipes were used in the feed and 141 permeate stream, respectively. The concentrate flow was monitored at the exit of the third vessel and the permeate flow was monitored at the exit of each pressure vessel. These flows were controlled by adjusting the opening of a glove valve and the power output of the pump

144 using a variable frequency drive. The permeate and concentrate were recirculated into the 145 feed reservoir. A chiller/heater unit (Aqua Cooler S360PD-CT, Chester Hill, NSW, Australia) 146 connected to stainless steel heat exchanging pipes was used to control the feed solution 147 temperature in the feed reservoir. 
148 Three different LPRO membranes namely ESPA2-4040 (Hydranautics, Oceanside, CA, 149 USA), TFC-HR 4040 (Koch Membrane Systems, San Diego, CA, USA) and TMG10 (Toray, 150 Tokyo, Japan) were used (Table 2). These PA-based LPRO membranes are commonly used 151 for brackish water treatment. The ESPA2 and TFC-HR membranes have been deployed in 152 several full-scale RO installations in the USA and Australia for potable water reuse 153 applications [13].

\section{[Figure 1]}

[Table 2]

156 2.4. Filtration protocols

157 Prior to the first filtration experiment, the analyte stock solution of the selected TrOCs was dosed into $100 \mathrm{~L}$ RO feed water at a ratio of $10 \mathrm{~mL}$-stock/100L-water to obtain approximately $5-20 \mu \mathrm{g} / \mathrm{L}$ of each TrOC. The membrane system was then operated at approximately $300 \mathrm{kPa}$ for at least 12 hours before the first samples were taken for analysis. The standard system operating condition used in this investigation was system permeate flux $20 \mathrm{~L} / \mathrm{m}^{2} \mathrm{~h}$ and feed temperature $20^{\circ} \mathrm{C}$. The impact of feed temperature was first investigated by incrementally increasing feed temperature from 10 to $35^{\circ} \mathrm{C}$. During the experiment, the system permeate flux was maintained at $20 \mathrm{~L} / \mathrm{m}^{2} \mathrm{~h}$. The impact of permeate flux was investigated by first adjusting permeate flux to $30 \mathrm{~L} / \mathrm{m}^{2} \mathrm{~h}$. Then, the permeate flux was stepwise decreased down to $10 \mathrm{~L} / \mathrm{m}^{2} \mathrm{~h}$. The feed temperature during the experiment was maintained at $20 \pm 0.1{ }^{\circ} \mathrm{C}$. The system recovery was maintained at $25 \%$ for all experiments. It is noteworthy that full-scale RO plants are operated at up to $85 \%$ water recovery [14] and the increase in system recovery can decrease solute rejection [9].

170 Following experiments described above, chemical cleaning was conducted using $\mathrm{NaOH}$ 171 solution ( $\mathrm{pH}$ 11-11.5). The chemical cleaning protocols include: (a) flushing the RO system 172 with $150 \mathrm{~L}$ of tap water; (b) recirculating $\mathrm{NaOH}$ solution for 1 hour at $35^{\circ} \mathrm{C}$; (c) soaking with 173 the $\mathrm{NaOH}$ solution for 3 hours; (d) recirculating the $\mathrm{NaOH}$ solution for 1 hour at $35^{\circ} \mathrm{C}$; (e) 174 flushing the RO system with $150 \mathrm{~L}$ of tap water. During the chemical recirculation, glove valve installed in the exit of the feed stream (Figure 1) was fully opened in order to minimise permeation through LPRO membranes, and feed flow was maintained at $24 \mathrm{~L} / \mathrm{min}$. Following

177 the chemical cleaning, the membrane system was operated using the RO feed water at 
$181 \quad$ Rejection $R[\%]=\left(1-\frac{C_{p}}{C_{f}}\right) \times 100$ approximately $300 \mathrm{kPa}$ for at least 12 hours. Then, feed and permeate samples were collected under the standard system operating condition (i.e. system permeate flux $20 \mathrm{~L} / \mathrm{m}^{2} \mathrm{~h}$ and feed temperature $20^{\circ} \mathrm{C}$ ). The rejection of chemicals was calculated using the following equation.

182 where $C_{p}$ and $C_{f}$ are permeate and feed concentrations, respectively.

\subsection{Analytical techniques}

\subsubsection{Sample collection}

Samples were collected in 0.5 L amber glass bottles. Sample volume taken for validation was $0.5 \mathrm{~L}$. Immediately after sampling $100 \mu \mathrm{L}$ of the $1 \mathrm{mg} / \mathrm{L}$ surrogate standard stock was added to each sample and well mixed before commencement of extraction. Samples were extracted immediately after sampling otherwise stored in the dark at $4{ }^{\circ} \mathrm{C}$ and extracted within 48 hours.

\subsubsection{Solid phase extraction}

Solid phase extraction (SPE) of TrOCs in each sample was performed using a method previously reported elsewhere [3]. TrOCs were extracted onto $500 \mathrm{mg}$ hydrophilic/lipophilic balance (HLB) solid-phase extraction SPE cartridges (Waters, Millford, MA, USA). Cartridges were pre-conditioned with tert-butyl methyl ether (MTBE), methanol, and Milli-Q water. Samples were drawn through the cartridge at approximately $10 \mathrm{~mL} / \mathrm{min}$. The cartridges were then rinsed with Milli-Q water $(5 \mathrm{~mL})$, dried and stored at $4{ }^{\circ} \mathrm{C}$ in sealed bags under nitrogen until elution. Target TrOCs were eluted from the cartridges with methanol followed by methanol/MTBE under gravity. The solvent was removed under nitrogen to approximately $1 \mathrm{~mL}$ using a solvent evaporator (Turbovap, Caliper Life Sciences, Hopkinton, MA, USA). The residue was transferred to a $2 \mathrm{~mL}$ amber auto-sampler vial. $50 \mu \mathrm{L}$ of the internal standard was added to each sample before capping with crimped seal.

\subsubsection{Liquid Chromatography (LC) - tandem Mass Spectrometry (MS)}

TrOCs were chromatographed using an Agilent (Palo Alto, CA, USA) 1200 series HPLC system equipped with a 150 x $4.6 \mathrm{~mm}, 5 \mu \mathrm{m}$ particle size, Luna C18 (2) column (Phenomenex, Torrence CA, USA). An API 4000 triple quadrupole mass spectrometer 
205 (Applied Biosystems, Foster City, CA, USA) equipped with a turbo-V ion source employed 206 in both positive and negative Electrospray ionisation (ESI) modes for all target compounds 207 except $17 \alpha$-estradiol which was analysed using atmospheric-pressure chemical ionisation 208 (APCI) in positive mode. Using multiple reaction monitoring (MRM) two precursor ion 209 product ion transitions for all target compounds and isotope labelled surrogates were 210 monitored for unequivocal confirmation. Only the first transition was used for quantitation.

211 Relative retention times of the analyte and isotopically labelled surrogate standard were also 212 monitored to ensure correct identification.

213 The use of isotope labelled versions of target compounds enabled quantification by isotope 214 dilution which enables losses due to incomplete extraction to be accounted for. An isotopic 215 version of each of the organic chemicals investigated here was used as their internal standard 216 to account for any losses during SPE as well as changes in the final volume. Isotopically 217 labelled versions were not available for metsulfuron-methyl, molinate, and trichlorfon. Thus, 218 carbamazepine D10 was used as the internal standard for these chemicals to account for any 219 changes in the final volume.

220 Both ESI and APCI in positive and negative modes were investigated for all standards to 221 establish the best ionization configuration. To determine suitable precursor ions a solution of each standard was directly infused into the ion source and scanned using quadrupole 1 (Q1) from $m / z 50-450$. The most intense ion observed was used to determine optimal source parameters such as declustering potential, collision energy and collision cell exit potential for each of up to 8 product ions detected in quadrupole 2 (Q2). Precursor-product ion transitions were incorporated into ESI positive, ESI negative or APCI positive methods and run using the chromatographic conditions stated above. For each analyte and surrogate standard the two most intense transitions were used in the final methods.

229 The instrument was calibrated at the beginning of each analytical run. Using working stocks, method calibration standards were prepared at $0.5,1,5,10,50,100,500$ and $1000 \mathrm{ng} / \mathrm{mL}$ in methanol. For each calibration standard, $100 \mathrm{ng}$ and $50 \mathrm{ng}$ of surrogate and internal standard respectively were added so that a relative response versus relative concentration curve can be generated. At least six calibration points were used for each target compound. Recoveries of

234 target compounds from both Milli-Q grade and RO feed water were determined by spiking 
and extracting samples at 10, 100 and $1000 \mathrm{ng} / \mathrm{L}$. Due to presence of some compounds in RO feed water, recoveries were determined only at $100 \mathrm{ng} / \mathrm{L}$ for this matrix.

\subsubsection{General water quality analysis}

238 During RO filtration experiments, $\mathrm{pH}$, electrical conductivity and temperature of solutions 239 was measured using Orion 4-Star Plus pH/conductivity meter (Thermo Fisher Scientific, 240 Waltham, MA, USA).

\section{Results and discussion}

\subsection{Analytical technique development and validation}

243 Recoveries of the other TrOCs from Milli-Q water and RO feed are summarised in

244 Supplementary Material Table S3. All target TrOCs were recovered within satisfactory 245 tolerances with the exception of molinate and trichlofon which were poorly recovered. To 246 mitigate this low recovery, higher feed concentrations for these two compounds were used for 247 the RO filtration work. On the other hand, di-n-butyl phthalate recoveries were significantly 248 affected by background contamination, thus its reporting levels were adjusted in this investigation accordingly. It is noteworthy that for quantification purpose any variations in recovery of the target analysts were corrected using the isotopic standards to remove any interference from the variation in recovery.

252 The calibrations and reporting detection limits of the tested TrOCs are summarised in 253 Supplementary Material Table S4. The instrument detection limit (IDL) was determined as 254 the lowest concentration of a standard that affords a signal to noise ratio $(\mathrm{s} / \mathrm{n})$ of 3 or greater. 255 The method detection limit (MDL) was the concentration of a target compound in sample that has been processed through the entire method giving a $\mathrm{s} / \mathrm{n}$ greater or equal to 3 . Reporting

257 limits were determined as being the greatest value of either the $2^{\text {nd }}$ lowest calibration point or 2583 times the MDL. Reporting limits were also dependant on any background contamination 259 present in analysed samples. Reporting limits in the RO feed were up to five times higher 260 than those in Milli-Q water (Supplementary Material Table S4). Details of the optimization 261 are summarized in Supplementary Material Table S5 and S6. The molecular structures of all 262 precursor ions and proposed structures of the monitored product ions are summarized in 263 Supplementary Material Table S7. 
264 Of the 10 TrOCs, dichloroprop, bisoprolol, varazolol, and molinate were detected in the RO 265 feed solution collected at a full-scale plant at slightly above their reporting detection limits of $2665,20,7$, and $11 \mathrm{ng} / \mathrm{L}$, respectively. The concentrations of other TrOCs were below the 267 detection limits reported in Supplementary Material Table S4. For validation purpose, if the 268 target TrOC was not detectable in the RO permeate, the reporting detection limit was used to 269 calculate a minimum rejection value.

\subsection{Validation during $R O$ filtration}

271 3.2.1. Effects of physicochemical properties of TrOCs and membranes

272 The target validation rejection of $90 \%$ of neutral TrOCs could be readily achieved by all three 273 LPRO membranes (Table 3). The neutral TrOCs selected here have the molecular weight of 274 over $180 \mathrm{~g} / \mathrm{mol}$ whereas the molecular weight cut-off of LPRO membranes is reported to be 275 about $100 \mathrm{~g} / \mathrm{mol}$ [15]. In fact, Fujioka et al. [16] evaluated the rejection of neutral compounds 276 (i.e. N-nitrosamines) using a laboratory-scale setup and reported that neutral compounds with 277 the molecular weight of over $114 \mathrm{~g} / \mathrm{mol}$ exhibited greater than $90 \%$ rejection by five different 278 LPRO membranes that are often used for water recycling applications.

279 The target validation rejection of $99 \%$ of charged chemicals were also achieved using all 280 three LPRO membranes with only two exceptions. Rejections of bisoprolol and carazolol by 281 the TFC-HR membrane were $97.7 \%$ and 97.2\%, respectively (Table 3). These two TrOCs are 282 positively charged and TFC-HR has the highest water permeability compared to the other 283 LPRO membranes investigated here. The low rejection of these positively charged TrOCs 284 can be explained by electrostatic attraction with the negatively charged active skin layer 285 surface of the LPRO membranes, causing a localised increase in concentration at the membrane surface, and leading to a low rejection. Verliefde et al. [17] called this phenomenon as "charge concentration polarisation". The target validation rejection of $99 \%$ was achieved with all negatively charged TrOCs (i.e. dichloroprop, metsulfuron-methyl and penicillin V) examined here. The active skin layer of typical LPRO membranes is negatively changed $[18,19]$. In fact, two of the LPRO membranes used in this study (ESPA2 and TFCHR) have a negative charge (-11 and $-23 \mathrm{mV}$, respectively) at the test solution $\mathrm{pH}$ (i.e. $\mathrm{pH}$ 292 7.7) [20]. Thus, high rejection of negatively charged TrOCs can be obtained due to electrostatic repulsion between these solutes and the membrane surface. 
294 Penicillin V was successfully incorporated in the analytical method described earlier.

295 However, it was detectable in the RO permeate of the TMG membrane only (Table 3). Thus, 296 the validation of Penicillin V rejection was omitted from subsequent experiments. Significant 297 decrease in pirimiphos-ethyl concentration in the RO feed was observed. Concentration of 298 this TrOC in the feed decreased from 10,000 ng/L to 80-140 ng/L after 12 hours of filtration. 299 Pirimiphos-ethyl has the highest hydrophobicity among TrOCs selected here $(\log D=5.1)$.

300 Thus, its adsorption onto membrane surface due to hydrophobic interaction can possibly be attributed to the decreasing pirimiphos-ethyl concentration in the feed $[21,22]$. It is noteworthy that pirimiphos-ethyl rejection calculation was conservative and was based on its measured concentrations in the feed and permeate. Nevertheless, the calculated rejection (94$96 \%$ ) was still above the target validation value of $90 \%$.

The validation was further examined using the rejections of eight other TrOCs (i.e. Nnitrosamines) that were evaluated by RO membranes (i.e. ESPA2 and TFC-HR) using the same pilot-scale system $[9,23]$. N-nitrosamines are uncharged and generally hydrophilic at the environment $\mathrm{pH}$ (e.g. $\mathrm{pH}$ 6-8). The target validation rejection of each $\mathrm{N}$-nitrosamine was achieved under the standard operating conditions (Table 4). The results reported here support that the rejection targets determined based on the qualitative prediction framework can be applicable to estimate the rejection of a variety of TrOCs.

\section{[Table 3]}

314 There was an apparent variation in the rejection of TrOCs among the three tested RO 315 membranes (i.e. ESPA2, TFC-HR and TMG). Although the relationship between membrane 316 permeability and conductivity rejection could be clearly observed, this relationship is not 317 readily transferable to the rejection of TrOCs (Figure 2). Nevertheless, it is apparent that the 318 ESPA2 which has the lowest water permeability amongst the three membranes examined 319 here exhibits high and less scattered TrOC rejection. On the other hand, rejections of the nine 320 TrOCs to be validated in this study by the TMG and TFC-HR membranes scattered quite 321 widely. In the pore-flow model, membrane permeability increases and solute rejection 322 decreases with increasing the free-volume hole-size of RO membrane active skin layer [24]. 323 In addition to free-volume hole-size, the porosity of the active skin layer has been suggested 
324 as an important factor determining the membrane's separation performance [25].

325 Nevertheless, the porosity of the active skin layer cannot be accurately quantified by any 326 analytical techniques available to date.

\subsubsection{Effects of operating conditions}

329 Variation in operating conditions is often seen at full-scale RO plants. For example, seasonal 330 variation in $\mathrm{RO}$ feed temperature at a full-scale plant can be over $10^{\circ} \mathrm{C}[26,27]$. Although

331 full-scale RO systems deployed for water recycling applications commonly employ a similar average flux of 17-21 L/m² $\mathrm{h}$ [14], a large variation in local permeate flux (e.g. 10-25 L/m² h) in an RO stage can also be expected [9]. Changes in these operating conditions including

334 permeate flux, feed temperature may exert a considerable influence on the rejection of TrOCs by LPRO membrane [28]. Chemical cleaning may modify the PA structure of the RO active skin layer, causing a deterioration in TrOC rejection [29]. Thus, the impact of operating conditions and chemical cleaning on the validation results was investigated in this study.

338 Conductivity rejection by the ESPA2 membrane decreased from 99.3 to $98.3 \%$ as the permeate flux decreased from 30 to $10 \mathrm{~L} / \mathrm{m}^{2} \mathrm{~h}$ (Figure $3 \mathrm{a}$ ). On the other hand, the rejection of

340 these TrOCs by the ESPA2 membrane remained almost constant for the increased permeate 341 flux. A similar trend was observed for the TMG membrane (Figure 3c). When the TFC-HR 342 membrane was used, the impact of the increased permeate flux was particularly apparent for 343 the rejection of two positively charged TrOCs (i.e. carazolol and bisoprolol) (Figure 3b). 344 These two TrOCs exhibited the lowest rejections (97-98\%) among the TrOCs that concentrations in the permeate were above their reporting detection limits.

347 In general, an increase in feed temperature resulted in a decrease in conductivity rejection, 348 while the impact on TrOC rejection was negligible (Figure 4). Regardless of the variation in 349 feed temperature, rejections of both neutral and charged TrOCs by the ESPA2 membrane 350 were above the target validation values (Figure 4). Similar results were observed with the 351 TMG membrane except the two positively charged TrOCs (i.e. carazolol and bisoprolol) at 352 feed temperature of 30 and $35{ }^{\circ} \mathrm{C}$ (Figure 4). The rejections of these positively charged 
353 TrOCs by the TFC-HR membrane were also observed at lower than their rejection validations

354 (Figure 4). The decreased TrOC rejection against increased feed temperature is likely to occur due to an increase in diffusivity of solutes through membrane [28]. The results reported

356 here indicate that the rejections of positively charged TrOCs selected here by the TFC-HR membrane are more likely to fall below their target rejection validations during a hot weather period.

\section{[Figure 4]}

360 Effects of chemical cleaning were also investigated. Chemical cleaning resulted in a small but 361 discernible decrease in conductivity rejection by all LPRO membranes (Figure 5). This implies that chemical cleaning can cause a negative impact on solute rejection. In fact, feed pressure to maintain the permeate flux of $20 \mathrm{~L} / \mathrm{m}^{2} \mathrm{~h}$ commonly decreased by $3-5 \%$ for all

364 LPRO membranes as a result of chemical cleaning, indicating that permeability of the membranes increased. A previous study has reported the rejection of several TrOCs is inversely proportional to membrane permeability [16]. However, the impact of chemical cleaning on TrOC rejection was not apparent. After chemical cleaning, the rejection of triclorfon by the ESPA2 membrane decreased to below the validation target of $90 \%$ (Figure 5a). It is noteworthy that when the filtration experiment was performed after the chemical cleaning, triclorfon concentrations in the feed and permeate were very low (48 and $<5 \mathrm{ng} / \mathrm{L}$, respectively), resulting in a rather low rejection value. Despite the inconclusive nature of the data reported here regarding the impact of chemical cleaning on TrOC rejection, it is noteworthy that extended chemical cleaning simulating multiple chemical cleanings over the years may cause deterioration in compound rejection as previously reported in the literature [29].

\section{[Figure 5]}

\section{4. Conclusions}

378 A protocol to validate the rejection of TrOCs was developed for decision making support 379 regarding the monitoring level required for potable water reuse. Analytical method was 380 successfully developed for quantifying the concentration of 10 TrOCs initially selected in this 381 study. The results show that LPRO membranes can achieve more than $90 \%$ of all neutral TrOCs selected which ensures that the rejection diagram previously developed based on their 
physicochemical properties is valid. However, the validation target of $99 \%$ of two charged

384 TrOCs (i.e. bisoprolol and carazolol) could not be achieved with the TFC-HR membrane.

385 This may be because bisoprolol and carazolol are both positively charged and the TFC-HR

386 has the highest water permeability amongst all three LPRO membranes investigated here.

387 The results also demonstrate that LPRO membrane with low water permeability is more 388 likely to satisfy the validation target. Operating conditions including permeate flux, feed temperature and chemical cleaning can exert a considerable impact on conductivity rejection by the three LPRO membranes investigated here. However, only feed temperature showed an apparent impact on the rejection of TrOCs. The decreased rejection of TrOCs with increasing temperature may be due to the increased diffusivity through the membranes. Indeed, the rejection of positively charged TrOCs is more likely to fall below their target rejection validation value during the summer when the feed temperature is high.

\section{Acknowledgements}

396 This work was supported by Seqwater.

397

398

399

400

401

402

403

404

405

406

407

408

409

410

411

412

413

414

\section{References}

[1] R.P. Schwarzenbach, B.I. Escher, K. Fenner, T.B. Hofstetter, C.A. Johnson, U. von Gunten, B. Wehrli, The Challenge of Micropollutants in Aquatic Systems, Science, 313 (2006) 1072-1077.

[2] W.H. Traves, E.A. Gardner, B. Dennien, D. Spiller, Towards indirect potable reuse in south east Queensland, Water Sci. Technol., 58 (2008) 153-161.

[3] A.A. Alturki, N. Tadkaew, J.A. McDonald, S.J. Khan, W.E. Price, L.D. Nghiem, Combining MBR and NF/RO membrane filtration for the removal of trace organics in indirect potable water reuse applications, J. Membr. Sci., 365 (2010) 206-215.

[4] A.R.D. Verliefde, S.G.J. Heijman, E.R. Cornelissen, G.L. Amy, B. Van der Bruggen, J.C. van Dijk, Rejection of trace organic pollutants with high pressure membranes (NF/RO), Environ. Prog., 27 (2008) 180-188.

[5] K.O. Agenson, J.-I. Oh, T. Urase, Retention of a wide variety of organic pollutants by different nanofiltration/reverse osmosis membranes: controlling parameters of process, J. Membr. Sci., 225 (2003) 91-103.

[6] S.A. Snyder, S. Adham, A.M. Redding, F.S. Cannon, J. DeCarolis, J. Oppenheimer, E.C. Wert, Y. Yoon, Role of membranes and activated carbon in the removal of endocrine disruptors and pharmaceuticals, Desalination, 202 (2007) 156-181. 
[7] Y. Yoon, P. Westerhoff, S.A. Snyder, E.C. Wert, J. Yoon, Removal of endocrine disrupting compounds and pharmaceuticals by nanofiltration and ultrafiltration membranes, Desalination, 202 (2007) 16-23.

[8] C. Bellona, J.E. Drewes, P. Xu, G. Amy, Factors affecting the rejection of organic solutes during NF/RO treatment - A literature review, Water Res., 38 (2004) 27952809.

[9] T. Fujioka, S.J. Khan, J.A. McDonald, A. Roux, Y. Poussade, J.E. Drewes, L.D. Nghiem, Modelling the rejection of N-nitrosamines by a spiral-wound reverse osmosis system: Mathematical model development and validation, J. Membr. Sci., 454 (2014) 212-219.

[10] A.R.D. Verliefde, E.R. Cornelissen, S.G.J. Heijman, J.Q.J.C. Verberk, G.L. Amy, B. Van der Bruggen, J.C. van Dijk, Construction and validation of a full-scale model for rejection of organic micropollutants by NF membranes, J. Membr. Sci., 339 (2009) $10-20$.

[11] V. Yangali-Quintanilla, A. Verliefde, T.U. Kim, A. Sadmani, M. Kennedy, G. Amy, Artificial neural network models based on QSAR for predicting rejection of neutral organic compounds by polyamide nanofiltration and reverse osmosis membranes, J. Membr. Sci., 342 (2009) 251-262.

[12] Office of the Queensland Parliamentary Counsel, Public Health Regulation 2005, http://www.health.qld.gov.au/legislation/ (2005).

[13] T. Fujioka, S.J. Khan, Y. Poussade, J.E. Drewes, L.D. Nghiem, N-nitrosamine removal by reverse osmosis for indirect potable water reuse - A critical review based on observations from laboratory-, pilot- and full-scale studies, Sep. Purif. Technol., 98 (2012) 503-515.

[14] T. Fujioka, S.J. Khan, Y. Poussade, J.E. Drewes, L.D. Nghiem, N-nitrosamine removal by reverse osmosis for indirect potable water reuse - A critical review based on observations from laboratory-, pilot- and full-scale studies, Sep. Purif. Technol., 98 (2012) 503-515.

[15] J.E. Drewes, C. Bellona, M. Oedekoven, P. Xu, T.-U. Kim, G. Amy, Rejection of wastewater-derived micropollutants in high-pressure membrane applications leading to indirect potable reuse, Environ. Prog., 24 (2005) 400-409.

[16] T. Fujioka, S.J. Khan, J.A. McDonald, A. Roux, Y. Poussade, J.E. Drewes, L.D. Nghiem, N-nitrosamine rejection by nanofiltration and reverse osmosis membranes: The importance of membrane characteristics, Desalination, 316 (2013) 67-75.

[17] A.R.D. Verliefde, E.R. Cornelissen, S.G.J. Heijman, J.Q.J.C. Verberk, G.L. Amy, B. Van der Bruggen, J.C. van Dijk, The role of electrostatic interactions on the rejection of organic solutes in aqueous solutions with nanofiltration, J. Membr. Sci., 322 (2008) $52-66$. 
[18] S.S. Deshmukh, A.E. Childress, Zeta potential of commercial RO membranes: influence of source water type and chemistry, Desalination, 140 (2001) 87-95.

[19] M.H. Oo, S.L. Ong, Implication of zeta potential at different salinities on boron removal by RO membranes, J. Membr. Sci., 352 (2010) 1-6.

[20] T. Fujioka, S.J. Khan, J.A. McDonald, A. Roux, Y. Poussade, J.E. Drewes, L.D. Nghiem, N-nitrosamine rejection by reverse osmosis: Effects of membrane exposure to chemical cleaning reagents, Desalination, 343 (2014) 60-66.

[21] L.D. Nghiem, A.I. Schäfer, M. Elimelech, Removal of natural hormones by nanofiltration membranes: Measurement, modeling, and mechanisms, Environ. Sci. Technol., 38 (2004) 1888-1896.

[22] K. Kimura, G. Amy, J. Drewes, Y. Watanabe, Adsorption of hydrophobic compounds onto NF/RO membranes: an artifact leading to overestimation of rejection, J. Membr. Sci., 221 (2003) 89-101.

[23] T. Fujioka, S.J. Khan, J.A. McDonald, A. Roux, Y. Poussade, J.E. Drewes, L.D. Nghiem, Rejection of small solutes by reverse osmosis membranes for water reuse applications: A pilot-scale study, Desalination, 350 (2014) 28-34.

[24] Y. Kiso, K. Muroshige, T. Oguchi, M. Hirose, T. Ohara, T. Shintani, Pore radius estimation based on organic solute molecular shape and effects of pressure on pore radius for a reverse osmosis membrane, J. Membr. Sci., 369 (2011) 290-298.

[25] T. Sasaki, H. Tomioka, K. Nakatsuji, Composite semipermeable membrane, production process thereof, and element, fluid separation equipment and treatment method for boron-containing water using the same, in: U.S. Patent (Ed.) United States Patent, Toray Industries, Inc., USA, 2010.

[26] T. Fujioka, S.J. Khan, J.A. McDonald, A. Roux, Y. Poussade, J.E. Drewes, L.D. Nghiem, N-nitrosamine rejection by reverse osmosis membranes: A full-scale study, Water Res., 47 (2013) 6141-6148.

[27] E. Van Houtte, J. Verbauwhede, Operational experience with indirect potable reuse at the Flemish Coast, Desalination, 218 (2008) 198-207.

[28] T. Fujioka, L.D. Nghiem, S.J. Khan, J.A. McDonald, Y. Poussade, J.E. Drewes, Effects of feed solution characteristics on the rejection of $\mathrm{N}$-nitrosamines by reverse osmosis membranes, J. Membr. Sci., 409-410 (2012) 66-74.

[29] A. Simon, J.A. McDonald, S.J. Khan, W.E. Price, L.D. Nghiem, Effects of caustic cleaning on pore size of nanofiltration membranes and their rejection of trace organic chemicals, J. Membr. Sci., 447 (2013) 153-162. 
Table 1: Physicochemical characteristics, regulated concentrations and rejection categories of the selected TrOCs.

\begin{tabular}{|c|c|c|c|c|c|c|c|c|c|}
\hline $\mathrm{TrOC}^{\mathrm{a}}$ & $\begin{array}{l}\text { Molecular } \\
\text { formula [-] }\end{array}$ & $\begin{array}{l}\text { Molecula } \\
\text { r weight } \\
{[\mathrm{g} / \mathrm{mol}]}\end{array}$ & $\begin{array}{l}\mathrm{pK}_{\mathrm{a}} \\
\left(\mathrm{pK}_{\mathrm{b}}\right)^{\mathrm{b}} \\
{[-]}\end{array}$ & $\begin{array}{l}\log D \\
\text { at } \mathrm{pH} \\
7.4^{\mathrm{c}}[-]\end{array}$ & $\begin{array}{l}\text { PHR } \\
\text { guideline } \\
\text { value }^{\mathrm{d}}\end{array}$ & $\begin{array}{l}\text { Maximum } \\
\text { reported } \\
\text { concentration } \\
\text { in source } \\
\text { water }^{\mathrm{e}}[\mu \mathrm{g} / \mathrm{L}]\end{array}$ & $\begin{array}{l}\text { Health } \\
\text { ratio }^{\mathrm{e}}\end{array}$ & $\begin{array}{l}\text { Rejection } \\
\text { category }\end{array}$ & $\begin{array}{l}\text { Validation } \\
\text { target [\%] }\end{array}$ \\
\hline \multirow{3}{*}{ 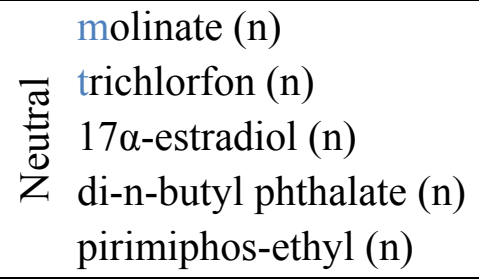 } & $\mathrm{C}_{8} \mathrm{H}_{15} \mathrm{NOS}$ & 187.3 & n.a. & 2.7 & 5 & $<0.5$ & $<0.100$ & 7 & 90 \\
\hline & $\mathrm{C}_{4} \mathrm{H}_{8} \mathrm{Cl}_{3} \mathrm{O}_{4} \mathrm{P}$ & 257.4 & 10.1 & 0.5 & 5 & $<1$ & $<0.200$ & 9 & 90 \\
\hline & $\mathrm{C}_{18} \mathrm{H}_{24} \mathrm{O}_{2}$ & 272.4 & 10.3 & 4.1 & 0.175 & 0.074 & 0.423 & 7 & 90 \\
\hline \multirow{5}{*}{ 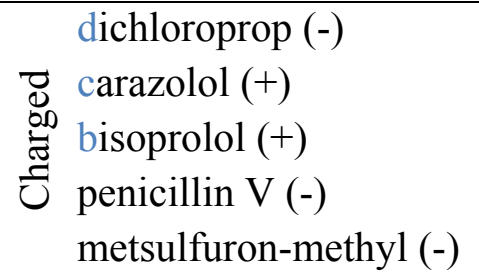 } & $\mathrm{C}_{9} \mathrm{H}_{8} \mathrm{Cl}_{2} \mathrm{O}_{3}$ & 235.1 & 3.0 & -0.7 & n.a. & n.a. & n.a. & 10 & 99 \\
\hline & $\mathrm{C}_{18} \mathrm{H}_{22} \mathrm{~N}_{2} \mathrm{O}_{2}$ & 298.4 & (9.7) & 1.4 & 0.35 & 0.12 & 0.343 & 10 & 99 \\
\hline & $\mathrm{C}_{18} \mathrm{H}_{31} \mathrm{NO}_{4}$ & 325.4 & $(9.7)$ & 0.1 & 0.63 & 0.37 & 0.587 & 10 & 99 \\
\hline & $\mathrm{C}_{16} \mathrm{H}_{18} \mathrm{~N}_{2} \mathrm{O}_{5} \mathrm{~S}$ & 350.4 & 3.4 & -1.9 & 1.5 & 2 & 1.333 & 10 & 99 \\
\hline & $\mathrm{C}_{14} \mathrm{H}_{15} \mathrm{~N}_{5} \mathrm{O}_{6} \mathrm{~S}$ & 381.4 & 3.5 & -0.3 & 30 & $<20$ & 0.667 & 10 & 99 \\
\hline
\end{tabular}

a (n) neutral; (+) positively charged; (-) negatively charged.

$489{ }^{\mathrm{b}}$ Chemaxon (http://www.chemicalize.org/).

$490{ }^{\mathrm{c}}$ Chemspider (http://www.chemspider.com/), data calculated using Advanced Chemistry Development (ACD/Labs).

491 d Public Health Regulation 2005 [12].

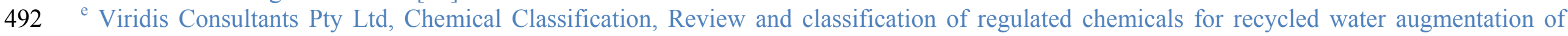
493 drinking water supplies in South East Queensland, (2011).

494 Supplementary Material Table S2.

495 n.a.: not available. 
496 Table 2: Performance data of membrane element provided by manufacturer.

\begin{tabular}{llllll}
\hline $\begin{array}{l}\text { Membrane } \\
\text { type }\end{array}$ & Manufacturer & $\begin{array}{l}\text { Membrane } \\
\text { area }\left[\mathrm{m}^{2}\right]\end{array}$ & $\begin{array}{l}\text { Product flow } \\
\text { rate }\left[\mathrm{m}^{3} / \mathrm{day}\right]\end{array}$ & $\begin{array}{l}\text { Salt rejection } \\
{[\%]}\end{array}$ & $\begin{array}{l}\text { Water } \\
\text { permeability } \\
{\left[\mathrm{L} / \mathrm{m}^{2} \text { hbar }\right]}\end{array}$ \\
\hline ESPA2 & Hydranautics & 7.9 & $7.2^{\mathrm{a}}$ & $99.6^{\mathrm{a}}$ & 4.4 \\
TFC-HR & KMS & 7.9 & $8.6^{\mathrm{b}}$ & $99.55^{\mathrm{b}}$ & 5.7 \\
TMG10 & Toray & 8.0 & $9.1^{\mathrm{c}}$ & $99.5^{\mathrm{c}}$ & 5.5 \\
\hline
\end{tabular}

$497{ }^{\mathrm{a}}$ Filtration condition: $1500 \mathrm{ppm} \mathrm{NaCl}, 1.05 \mathrm{MPa}, 25^{\circ} \mathrm{C}, \mathrm{pH}$ 6.5-7.0 and 15\% recovery.

$498{ }^{\mathrm{b}}$ Filtration condition: $2000 \mathrm{ppm} \mathrm{NaCl}, 1.55 \mathrm{MPa}, 25^{\circ} \mathrm{C}, \mathrm{pH} 7.5$ and $15 \%$ recovery.

$499{ }^{\mathrm{c}}$ Filtration condition: $500 \mathrm{ppm} \mathrm{NaCl}, 0.96 \mathrm{MPa}, 25^{\circ} \mathrm{C}, \mathrm{pH} 7.0$ and $15 \%$ recovery.

$500{ }^{\mathrm{d}}$ Measured with deionised water at $20{ }^{\circ} \mathrm{C}$ feed temperature using a single spiral wound 501 element. 
Table 3: Rejection of TrOCs in the RO feed by the (a) ESPA2, (b) TFC-HR and (c) TMG membranes (system permeate flux $20 \mathrm{~L} / \mathrm{m}^{2} \mathrm{~h}$, feed $\mathrm{pH} 7.65$, system recovery $25 \%$, feed temperature $20.0 \pm 0.1^{\circ} \mathrm{C}$ ). Values reported here are the average and ranges of duplicate samples.

\begin{tabular}{|c|c|c|c|c|c|c|c|}
\hline \multirow[t]{2}{*}{ Parameter } & \multirow{2}{*}{$\begin{array}{l}\text { Target } \\
\text { Rejection } \\
{[\%]}\end{array}$} & \multicolumn{6}{|c|}{ Rejection [\%]/Validation } \\
\hline & & ESPA2 & & TFC-HR & & TMG & \\
\hline molinate & 90 & $99.8 \pm 0.0$ & Yes & $98.3 \pm 0.3$ & Yes & $99.8 \pm 0.0$ & Yes \\
\hline trichlorfon & 90 & $99.9 \pm 0.0^{*}$ & Yes & $99.9 \pm 0.0 *$ & Yes & $99.4 \pm 0.0^{*}$ & Yes \\
\hline $17 \alpha$-estradiol & 90 & $99.8 \pm 0.0$ & Yes & $98.1 \pm 0.1$ & Yes & $98.7 \pm 0.0$ & Yes \\
\hline di-n-butyl phthalate & 90 & $97.3 \pm 0.0^{*}$ & Yes & $96.5 \pm 0.4$ & Yes & $91.5 \pm 0.0$ & Yes \\
\hline pirimiphos-ethyl & 90 & $96.0 \pm 0.0^{*}$ & Yes & $93.8 \pm 0.0 *$ & Yes & $96.3 \pm 0.0^{*}$ & Yes \\
\hline dichloroprop & 99 & $99.9 \pm 0.0^{*}$ & Yes & $99.4 \pm 0.0$ & Yes & $99.9 \pm 0.0^{*}$ & Yes \\
\hline carazolol & 99 & $99.8 \pm 0.0$ & Yes & $97.7 \pm 0.2$ & No & $99.5 \pm 0.1$ & Yes \\
\hline bisoprolol & 99 & $99.8 \pm 0.0$ & Yes & $97.2 \pm 0.2$ & No & $99.5 \pm 0.0$ & Yes \\
\hline penicillin V & 99 & N.D. & - & N.D. & - & $99.5 \pm 0.0^{*}$ & Yes \\
\hline metsulfuron-methyl & 99 & $99.9 \pm 0.0^{*}$ & Yes & $99.3 \pm 0.0$ & Yes & $99.9 \pm 0.0^{*}$ & Yes \\
\hline
\end{tabular}

$506 *$ Permeate concentration was below their detection limits.

507 N.D.: feed concentration was below their detection limits. 
Table 4: Rejection of N-nitrosamines in the RO feed by the ESPA2 and TFC-HR membranes (system permeate flux $20 \mathrm{~L} / \mathrm{m}^{2} \mathrm{~h}$, feed $\mathrm{pH} 8$, system 509 recovery $25 \%$, feed temperature $20.0 \pm 0.1^{\circ} \mathrm{C}$ ).

\begin{tabular}{|c|c|c|c|c|c|c|c|c|c|}
\hline Parameter & $\begin{array}{l}\text { Molecula } \\
\text { r weight } \\
{[\mathrm{g} / \mathrm{mol}]}\end{array}$ & $\begin{array}{l}\text { Log D at } \\
\text { pH } 8\end{array}$ & $\begin{array}{l}\text { Molecular } \\
\text { width (MWd) } \\
\text { [nm] }\end{array}$ & $\begin{array}{l}\text { Rejection } \\
\text { category a }\end{array}$ & $\begin{array}{l}\text { Target } \\
\text { Rejection }{ }^{\mathrm{a}} \\
{[\%]}\end{array}$ & \multicolumn{4}{|c|}{ Rejection [\%]/Validation } \\
\hline N-nitrosodimethylamine & 74.1 & 0.04 & 0.270 & 3 & 0 & 56 & Yes & 31 & Yes \\
\hline N-nitrosopyrrolidine & 100.1 & 0.44 & 0.318 & 8 & 20 & 93 & Yes & 71 & Yes \\
\hline N-nitrosodiethylamine & 102.1 & 0.75 & 0.322 & 8 & 20 & 94 & Yes & 85 & Yes \\
\hline $\mathrm{N}$-nitrosopiperidine & 114.1 & 0.89 & 0.325 & 8 & 20 & 98 & Yes & 94 & Yes \\
\hline N-nitrosodi-n-butylamine & 158.1 & 2.69 & 0.405 & 7 & 90 & 97 & Yes & N.A. & \\
\hline
\end{tabular}

N-nitrosodi-n-butylamine

511 N.A.: not available. 


\section{LIST OF FIGURES}

513 Figure 1: Schematic diagram of the pilot RO filtration system.

514 Figure 2: Rejection of conductivity and TrOCs in the RO feed as a function of water 515 permeability of LPRO membrane. Open symbol indicates that the permeate concentration was 516 below the instrumental detection limit.

517 Figure 3: Effects of average permeate flux on the rejection of conductivity and TrOCs in the 518 RO feed by the (a) ESPA2, (b) TFC-HR and (c) TMG membranes. Values reported here are 519 the averages of duplicate samples. Open symbol indicates that the permeate concentration was 520 below the instrumental detection limit. Dotted lines show the target validation rejections of 521 the neutral and charged TrOCs.

522 Figure 4: Effects of feed temperature on the rejection of conductivity and TrOCs in the RO 523 feed by the (a) ESPA2, (b) TFC-HR and (c) TMG membranes. Values reported here are the 524 averages of duplicate samples. Open symbol indicates that the permeate concentration was 525 below the instrumental detection limit. Dotted lines show the target validation rejections of 526 the neutral and charged TrOCs.

527 Figure 5: Effects of chemical cleaning on the rejection of conductivity and TrOCs in the RO 528 feed water by the (a) ESPA2, (b) TFC-HR and (c) TMG membranes. Values reported here are 529 the averages of duplicate samples. Open symbol indicates that the permeate concentration was 530 below the instrumental detection limit. Dotted lines show the target validation rejections of 531 the neutral and charged TrOCs. 


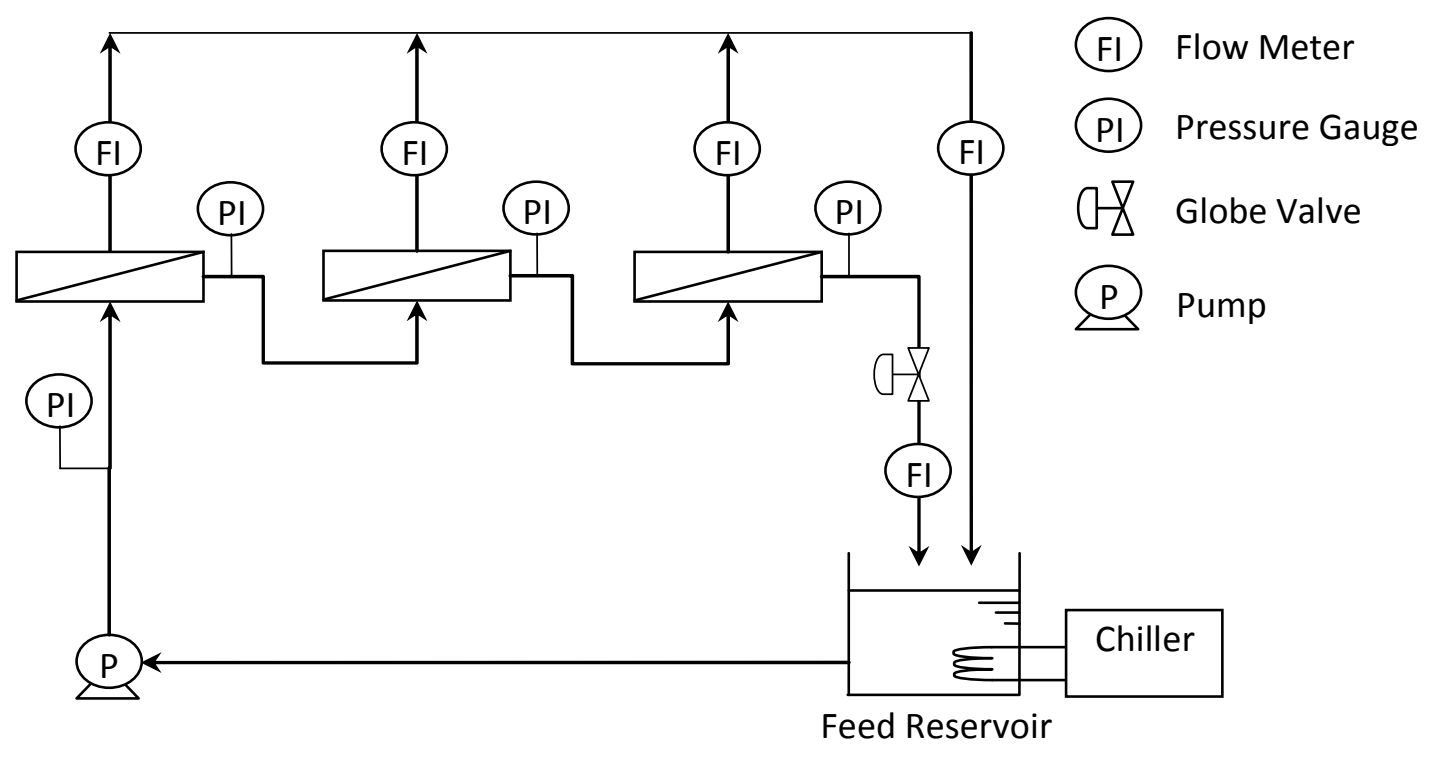

532

533 Figure 1 


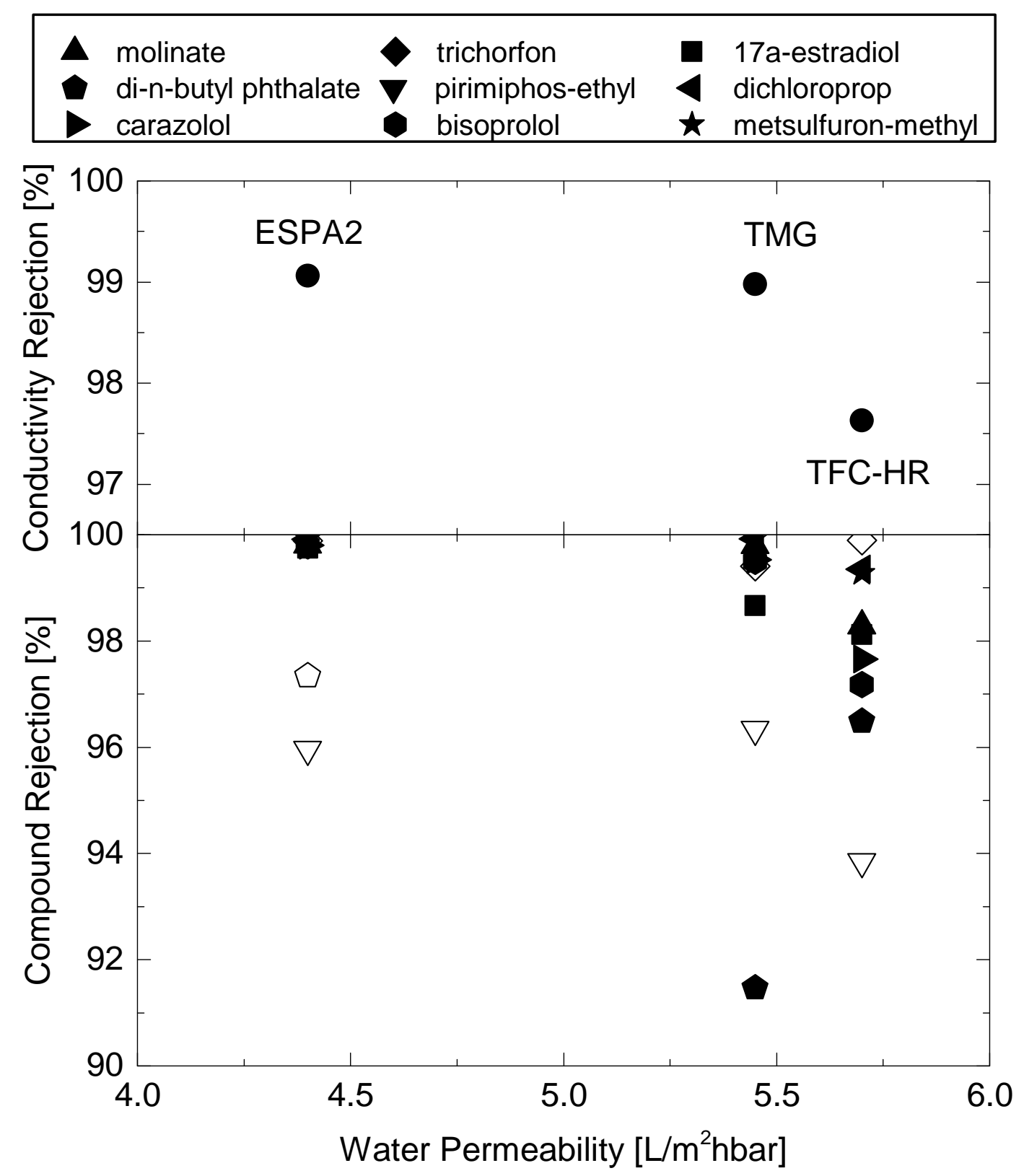

534

$535 \quad$ Figure 2 


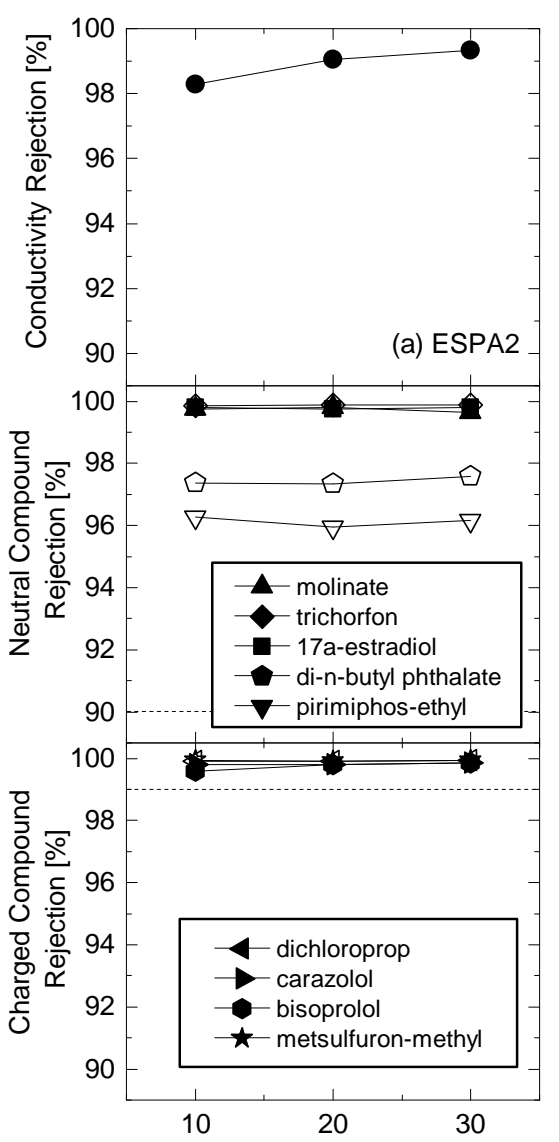

Average Permeate Flux $\left[\mathrm{L} / \mathrm{m}^{2} \mathrm{~h}\right]$

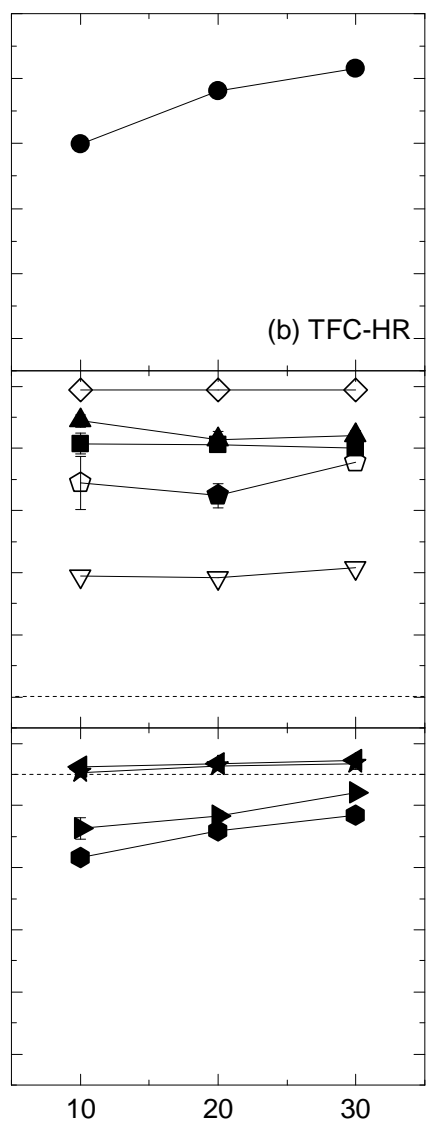

Average Permeate Flux [L/m² $\mathrm{h}]$

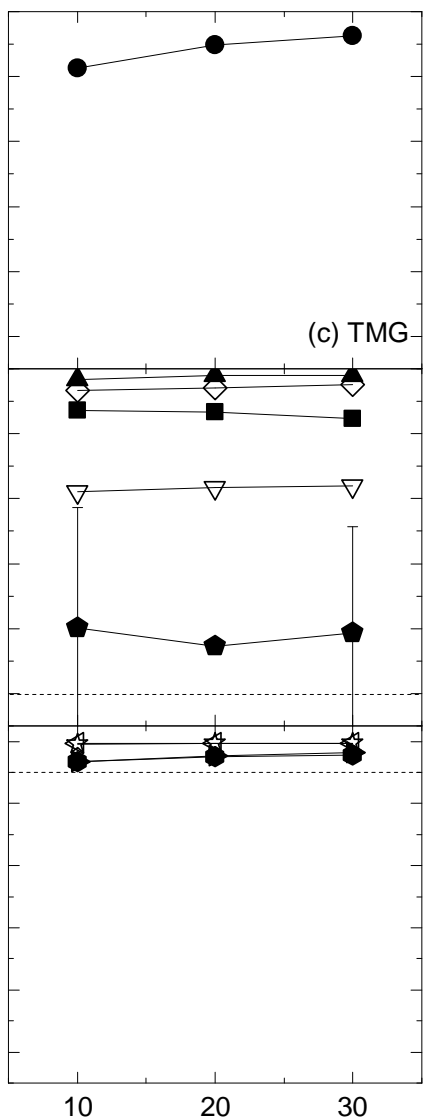

Average Permeate Flux $\left[\mathrm{L} / \mathrm{m}^{2} \mathrm{~h}\right]$

Figure 3 


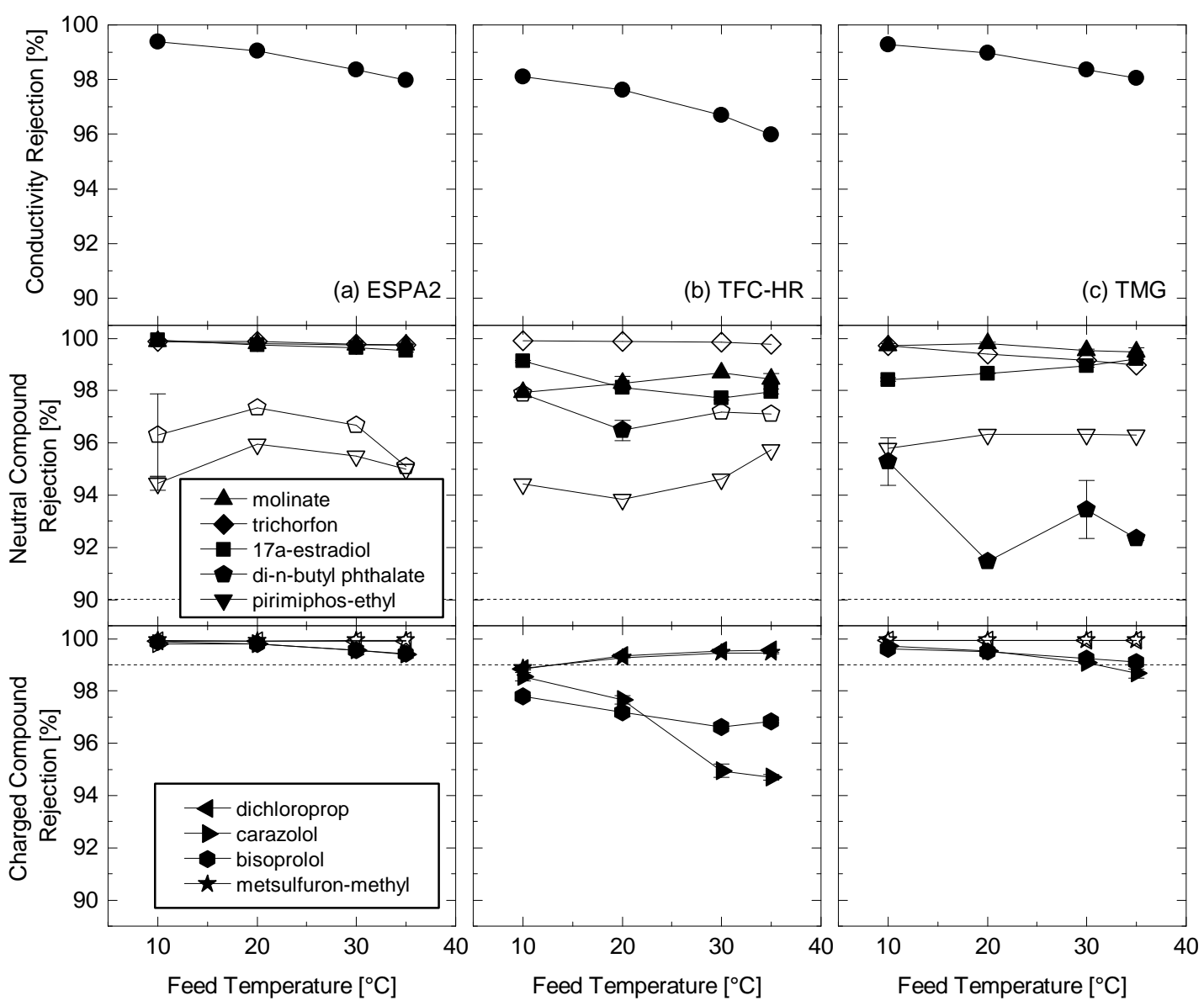

538

Figure 4 


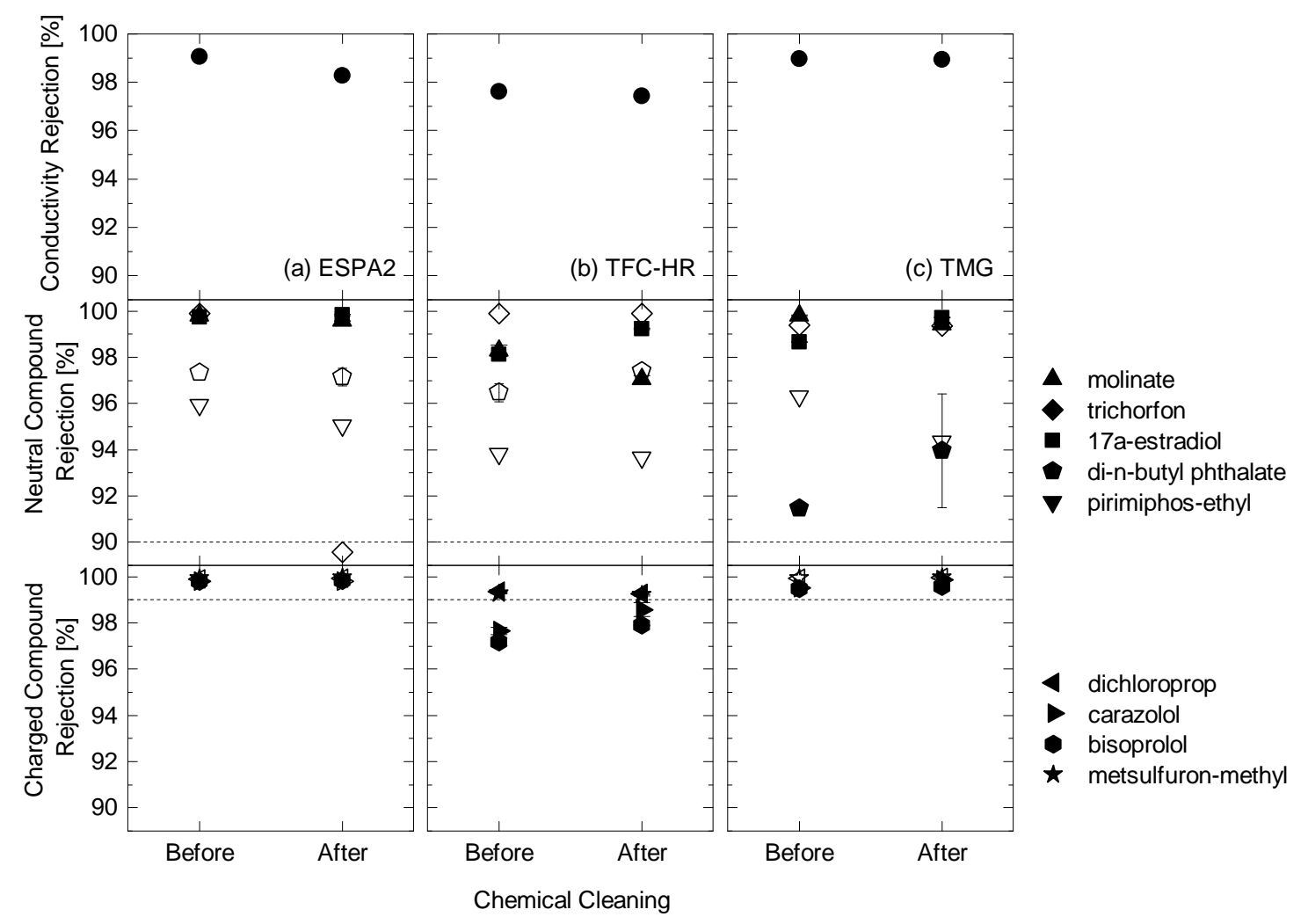

\section{$541 \quad$ Figure 5}




\title{
Validating the rejection of trace organic chemicals by reverse osmosis membranes using a pilot-scale system
}

\author{
Takahiro Fujioka $^{1, *}$, Stuart J. Khan ${ }^{2}$, James A. McDonald ${ }^{2}$, Long D. Nghiem ${ }^{1}$ \\ ${ }^{1}$ Strategic Water Infrastructure Laboratory, School of Civil Mining and Environmental \\ Engineering, The University of Wollongong, NSW 2522, Australia \\ ${ }^{2}$ UNSW Water Research Centre, School of Civil and Environmental Engineering, The \\ University of New South Wales, NSW 2052, Australia
}

\section{SUPPLEMENTARY MATERIAL}

* Corresponding author: Takahiro Fujioka, Email: takahiro@uow.edu.au, Ph +61 242214074 


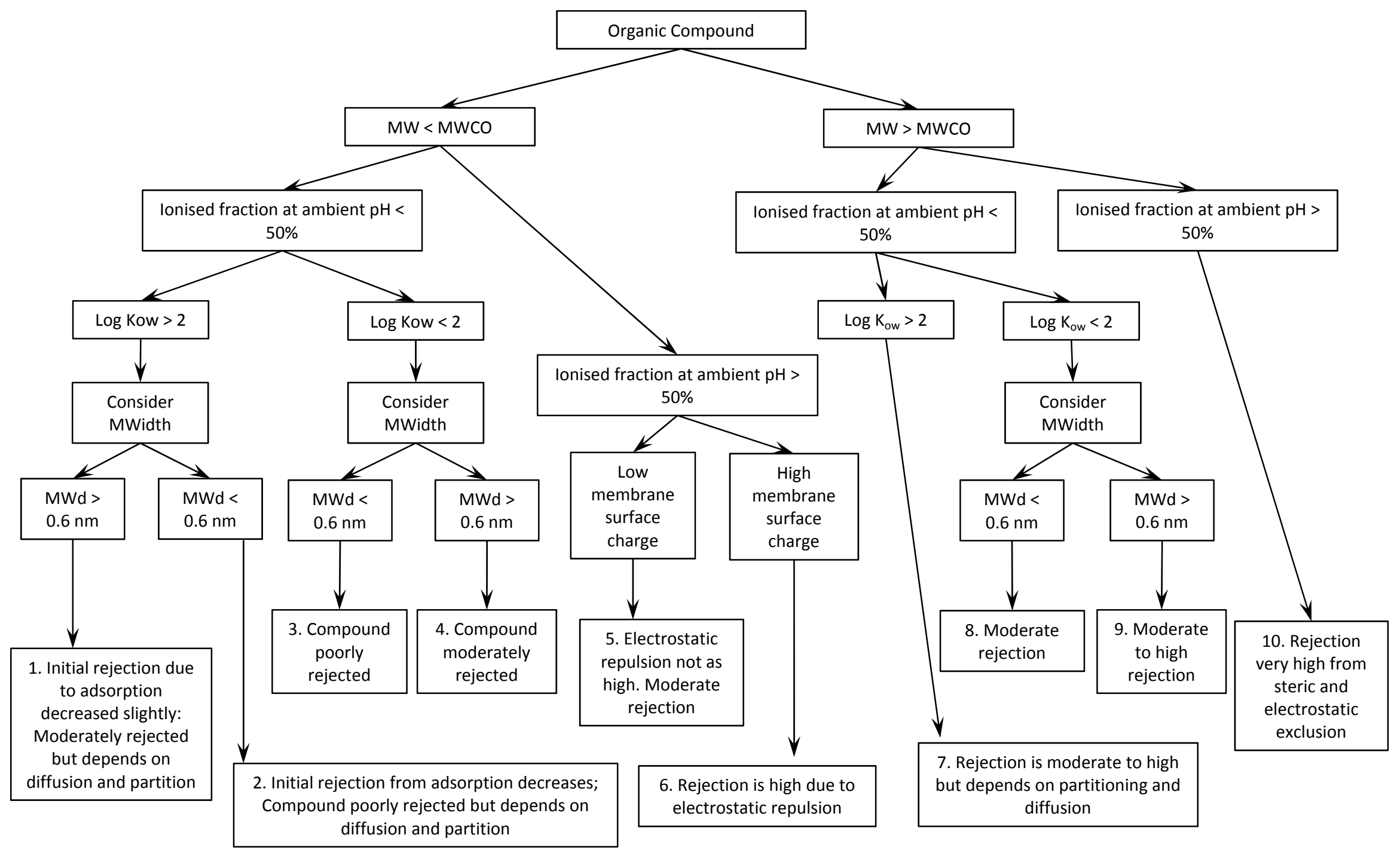

Figure S1: Modified membrane rejection diagram. (Viridis Consultants Pty Ltd, Chemical Classification, Review and classification of regulated chemicals for recycled water augmentation of drinking water supplies in South East Queensland, (2011)). 
1 Table S2: Rejection categories, assumed rejection and validation target. (Viridis

2 Consultants Pty Ltd, Chemical Classification, Review and classification of regulated

3 chemicals for recycled water augmentation of drinking water supplies in South East

4 Queensland, (2011)).

\begin{tabular}{|c|c|c|c|}
\hline $\begin{array}{l}\text { Rejection } \\
\text { category }\end{array}$ & Description & $\begin{array}{l}\text { Assumed } \\
\text { rejection } \\
{[\%]}\end{array}$ & $\begin{array}{l}\text { Validation } \\
\text { target [\%] }\end{array}$ \\
\hline 1 & $\begin{array}{l}\text { Initial rejection due to adsorption decreases slightly; } \\
\text { Moderately rejected but depend on diffusion and } \\
\text { partition }\end{array}$ & $20-90$ & 20 \\
\hline 2 & $\begin{array}{l}\text { Initial rejection from adsorption decreases; } \\
\text { Compound poorly rejected but depends on diffusion } \\
\text { and partition }\end{array}$ & $0-10$ & 0 \\
\hline 3 & Compound poorly rejected & $0-10$ & 0 \\
\hline 4 & Compound moderately rejected & $20-90$ & 20 \\
\hline 5 & $\begin{array}{l}\text { Electrostatic repulsion not as high: Moderate } \\
\text { rejection }\end{array}$ & $20-90$ & 20 \\
\hline 6 & Rejection is high due to electrostatic repulsion & $99-99.9$ & 99 \\
\hline 7 & $\begin{array}{l}\text { Rejection moderate to high but depends on } \\
\text { partitioning and diffusion }\end{array}$ & $90-99$ & 90 \\
\hline 8 & Moderate rejection & $20-90$ & 20 \\
\hline 9 & Moderate to high rejection & $90-99$ & 90 \\
\hline 10 & $\begin{array}{l}\text { Rejection very high from steric and electrostatic } \\
\text { exclusion }\end{array}$ & 99-99.9 & 99 \\
\hline
\end{tabular}

5 
6 Table S3: Recoveries of TrOCs with spiking concentrations of 10, 100, and 1,000 ng/L from

7 Milli-Q water and RO feed (mean \pm standard deviation of three replicates).

\begin{tabular}{lllll}
\hline TrOC & \multicolumn{3}{c}{ Milli-Q } & RO feed \\
\cline { 2 - 4 } & $10 \mathrm{ng} / \mathrm{L}$ & $100 \mathrm{ng} / \mathrm{L}$ & $1,000 \mathrm{ng} / \mathrm{L}$ & $100 \mathrm{ng} / \mathrm{L}$ \\
\hline 17a-estradiol & $81 \pm 2$ & $81 \pm 2$ & $79 \pm 3$ & $120 \pm 2$ \\
dichloroprop & $96 \pm 4$ & $88 \pm 1$ & $84 \pm 3$ & $95 \pm 2$ \\
di- $n$-butyl phthalate & $566 \pm 4$ & $154 \pm 1$ & $101 \pm 2$ & $455 \pm 8$ \\
bisoprolol & $79 \pm 11$ & $83 \pm 4$ & $78 \pm 6$ & $117 \pm 2$ \\
carazolol & $81 \pm 16$ & $86 \pm 12$ & $78 \pm 7$ & $106 \pm 4$ \\
metsulfuron-methyl & $80 \pm 31$ & $88 \pm 10$ & $93 \pm 6$ & $85 \pm 20$ \\
molinate & $30 \pm 20$ & $36 \pm 15$ & $35 \pm 8$ & $45 \pm 15$ \\
pirimiphos-ethyl & $86 \pm 3$ & $83 \pm 1$ & $78 \pm 4$ & $98 \pm 2$ \\
trichorfon & $37 \pm 15$ & $41 \pm 23$ & $37 \pm 13$ & $30 \pm 14$ \\
penicillin V & $86 \pm 12$ & $84 \pm 7$ & $75 \pm 3$ & $99 \pm 9$ \\
\hline
\end{tabular}


9 Table S4: Method quality parameters

\begin{tabular}{|c|c|c|c|c|c|c|c|}
\hline \multirow[t]{2}{*}{ TrOC } & \multirow[t]{2}{*}{ Method } & \multirow[t]{2}{*}{$\begin{array}{l}\text { Calibration } \\
\text { range }[\mathrm{ng} / \mathrm{L}]\end{array}$} & \multirow[t]{2}{*}{$\mathrm{R}^{2}$} & \multirow{2}{*}{$\begin{array}{l}\text { IDL } \\
\text { [pg on } \\
\text { column] }\end{array}$} & \multirow[t]{2}{*}{$\begin{array}{l}\mathrm{MDL} \\
{[\mathrm{ng} / \mathrm{L}]}\end{array}$} & \multicolumn{2}{|c|}{$\begin{array}{l}\text { Reporting limit } \\
{[\mathrm{ng} / \mathrm{L}]}\end{array}$} \\
\hline & & & & & & Milli-Q & RO feed \\
\hline 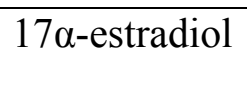 & $\begin{array}{l}\text { APCI } \\
\text { positive }\end{array}$ & $0.5-1000$ & 0.999 & 5 & 0.1 & 5 & 5 \\
\hline dichloroprop & $\begin{array}{l}\text { ESI } \\
\text { negative }\end{array}$ & $0.5-1000$ & 0.995 & 11 & 0.5 & 5 & 5 \\
\hline $\begin{array}{l}\text { di-n-butyl } \\
\text { phthalate }\end{array}$ & $\begin{array}{l}\text { ESI } \\
\text { positive }\end{array}$ & $0.5-1000$ & 0.985 & 6 & 0.02 & 50 & 250 \\
\hline bisoprolol & & $0.5-1000$ & 0.991 & 2 & 0.01 & 5 & 20 \\
\hline carazolol & & $1-1000$ & 0.994 & 6 & 0.02 & 5 & 10 \\
\hline $\begin{array}{l}\text { metsulfuron- } \\
\text { methyl }\end{array}$ & & $0.5-1000$ & 0.993 & 2 & 0.01 & 5 & 5 \\
\hline molinate & & $0.5-1000$ & 0.990 & 213 & 1 & 5 & 10 \\
\hline penicillin V & & $0.5-1000$ & 0.994 & 3 & 0.1 & 5 & 5 \\
\hline $\begin{array}{l}\text { pirimiphos- } \\
\text { ethyl }\end{array}$ & & $0.5-1000$ & 0.990 & 69 & 0.5 & 5 & 5 \\
\hline trichlorfon & & $1-1000$ & 0.996 & 32 & 0.4 & 5 & 5 \\
\hline
\end{tabular}

10 
Table S5: Optimized chemical dependent acquisition parameters

\begin{tabular}{|c|c|c|c|c|c|c|}
\hline TrOC & $\begin{array}{l}\text { Retention } \\
\text { time [min] }\end{array}$ & $\begin{array}{l}\text { Precursor } \\
\text { ion } \\
\text { molecular } \\
\text { weight } \\
{[\mathrm{g} / \mathrm{mol}]}\end{array}$ & $\begin{array}{l}\text { Product } \\
\text { ion } \\
\text { molecular } \\
\text { weight } \\
{[\mathrm{g} / \mathrm{mol}]}\end{array}$ & $\begin{array}{l}\text { Decluste } \\
\text { ring } \\
\text { potential } \\
{[\mathrm{V}]}\end{array}$ & $\begin{array}{l}\text { Collisi } \\
\text { on } \\
\text { energy } \\
{[\mathrm{eV}]}\end{array}$ & $\begin{array}{l}\text { Collisio } \\
\mathrm{n} \text { cell } \\
\text { exit } \\
\text { potenti } \\
\text { al [V] }\end{array}$ \\
\hline \multicolumn{7}{|l|}{ ESI positive } \\
\hline molinate-1 & 9.1 & 188.1 & 125.5 & 51 & 19 & 22 \\
\hline molinate-2 & 9.1 & 188.1 & 82.9 & 51 & 25 & 14 \\
\hline trichorfon-1 & 5.4 & 256.9 & 109.0 & 76 & 27 & 18 \\
\hline trichorfon-2 & 5.4 & 256.9 & 126.7 & 76 & 25 & 22 \\
\hline di-n-butylphthalate-1 & 10.1 & 279.2 & 148.9 & 61 & 19 & 26 \\
\hline di-n-butylphthalate-2 & 10.2 & 279.2 & 204.7 & 61 & 11 & 12 \\
\hline di-n-butylphthalate-D4-1 & 10.1 & 283.2 & 209.0 & 41 & 11 & 12 \\
\hline di-n-butylphthalate-D4-2 & 10.1 & 283.2 & 152.7 & 41 & 19 & 26 \\
\hline pirimiphos-ethyl-1 & 10.5 & 334.1 & 198.1 & 61 & 31 & 16 \\
\hline pirimiphos-ethyl-2 & 10.5 & 334.1 & 181.9 & 61 & 31 & 16 \\
\hline pirimiphos-ethyl-D10-1 & 10.5 & 344.1 & 198.7 & 91 & 33 & 18 \\
\hline pirimiphos-ethyl-D10-2 & 10.5 & 344.1 & 183.0 & 91 & 33 & 12 \\
\hline carazolol-1 & 5.2 & 299.1 & 115.6 & 76 & 29 & 20 \\
\hline carazolol-2 & 5.2 & 299.1 & 221.6 & 76 & 29 & 18 \\
\hline carazolol-D7-1 & 5.2 & 306.2 & 122.8 & 81 & 29 & 22 \\
\hline carazolol-D7-2 & 5.2 & 306.2 & 221.6 & 81 & 29 & 20 \\
\hline bisoprolol-1 & 5.8 & 326.2 & 115.8 & 76 & 25 & 20 \\
\hline bisoprolol-2 & 5.8 & 326.2 & 73.5 & 76 & 43 & 12 \\
\hline bisoprolol-D5-1 & 5.8 & 331.2 & 120.8 & 96 & 25 & 10 \\
\hline bisoprolol-D5-2 & 5.8 & 331.2 & 78.9 & 96 & 43 & 12 \\
\hline penicillin V-1 & 5.7 & 383.1 & 159.8 & 71 & 23 & 14 \\
\hline penicillin V-2 & 5.7 & 383.1 & 113.9 & 71 & 51 & 20 \\
\hline penicillin-V-D5-1 & 5.7 & 388.1 & 160.0 & 71 & 23 & 28 \\
\hline penicillin-V-D5-2 & 5.7 & 388.1 & 113.6 & 71 & 55 & 20 \\
\hline metsulfuron-methyl-1 & 4.5 & 382.0 & 167.0 & 71 & 23 & 10 \\
\hline metsulfuron-methyl-2 & 4.5 & 382.0 & 198.6 & 71 & 31 & 34 \\
\hline carbamazepine-D10 & 7.1 & 247.1 & 204.3 & 51 & 29 & 10 \\
\hline \multicolumn{7}{|l|}{ ESI negative } \\
\hline dichloroprop-1 & 6.1 & 232.8 & 160.7 & -50 & -18 & -9 \\
\hline dichloroprop-2 & 6.1 & 232.8 & 124.5 & -50 & -40 & -9 \\
\hline dichloroprop-D6-1 & 6.1 & 238.8 & 163.2 & -50 & -18 & -7 \\
\hline dichloroprop-D6-2 & 6.1 & 238.8 & 126.7 & -50 & -40 & -5 \\
\hline \multicolumn{7}{|l|}{ APCI positive } \\
\hline $17 \alpha$-estradiol-1 & 10.2 & 255.2 & 159.3 & 61 & 27 & 10 \\
\hline $17 \alpha$-estradiol-2 & 10.2 & 255.2 & 133.2 & 61 & 27 & 10 \\
\hline $17 \alpha$-estradiol-1-D4-1 & 10 & 259.1 & 161.1 & 61 & 27 & 8 \\
\hline $17 \alpha$-estradiol-1-D4-2 & 10 & 259.1 & 135.1 & 61 & 25 & 11 \\
\hline
\end{tabular}




\section{Optimisation of ion source parameters}

14 When employing the ESI mode, the mobile phases consisted of $5 \mathrm{mM}$ ammonium acetate in water (A) and $100 \%$ methanol (B) was pumped at a flow rate of $800 \mu \mathrm{L} / \mathrm{min}$. For positive

16 ESI analysis the eluents were held at $10 \% \mathrm{~B}$ for $0.50 \mathrm{~min}$ and then linearly ramped to $50 \%$ at

$170.51 \mathrm{~min}$. Thereafter, the eluents were increased linearly to $100 \%$ at $8 \mathrm{~min}$, then held at $100 \%$

$18 \mathrm{~B}$ for $2 \mathrm{~min}$ with a total run time of $14.4 \mathrm{~min}$. For negative ESI analysis, $10 \% \mathrm{~B}$ were held for

$190.50 \mathrm{~min}$, stepped to $60 \% \mathrm{~B}$ at $0.51 \mathrm{~min}$ and increased linearly to $100 \% \mathrm{~B}$ at $8 \mathrm{~min}$, then held 20 at $100 \% \mathrm{~B}$ for $3 \mathrm{~min}$ with a total run time of $14.4 \mathrm{~min}$. A 5 min equilibration step at $10 \% \mathrm{~B}$ was used at the beginning of each run.

22 When employing the APCI mode, the eluents consisted of $0.1 \% \mathrm{v} / \mathrm{v}$ formic acid in water (A)

23 and methanol (B) with the following ramp at a flow rate of $700 \mu \mathrm{L} / \mathrm{min} .60 \%$ B were held for

$245 \mathrm{~min}$, increased linearly to $100 \% \mathrm{~B}$ at $20 \mathrm{~min}$, and then held at $100 \% \mathrm{~B}$ for $3 \mathrm{~min}$ with a total

25 run time of $13 \mathrm{~min}$. A 3 min equilibrium step preceded injection. An injection volume of 10

$26 \mu \mathrm{L}$ was used for all methods.

Table S6: Optimised ion source parameters

\begin{tabular}{llll}
\hline & ESI positive & ESI negative & APCI positive \\
\hline curtain gas [psig] & 19 & 19 & 15 \\
collision gas [psig] & high & high & high \\
nebulizer current [mA] & 3 & -3 & 3 \\
temperature $\left[{ }^{\circ} \mathrm{C}\right]$ & 550 & 550 & 450 \\
ion source gas 1 [psig] & 60 & 60 & 40 \\
ion source gas 2 [psig] & 50 & 50 & N/A \\
run time [min] & 14.4 & 14.4 & 13 \\
\hline
\end{tabular}


29 Table S7: Molecular structures of target chemicals and proposed structures for product ions.

Dichloroprop

Carazolol




\begin{tabular}{lllll}
\hline & $\mathrm{Q} 1$ & structure & $\mathrm{Q} 2$ & proposed structure \\
\hline Carazolol D7 & 306 & 123 & \\
\hline
\end{tabular}

Metsulfuron-methyl 382

$167 \pi^{\mathrm{N}} \mathrm{O}^{\mathrm{N}} \mathrm{Y}^{\mathrm{O}}$

199

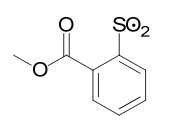

Molinate

188

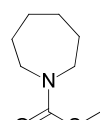

o-
126

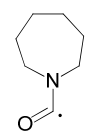

83

160

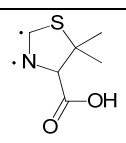

114

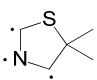

Penicillin V-D5

\section{8}

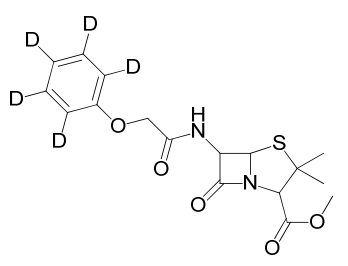

Pirimiphos-ethyl

334

160

$\int_{0}^{5} \mathrm{OH}$

114

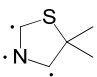

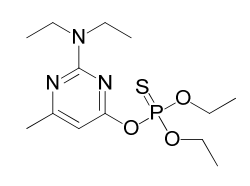

182

98

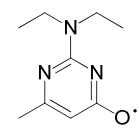

Pirimiphos-ethyl-D10 344 199

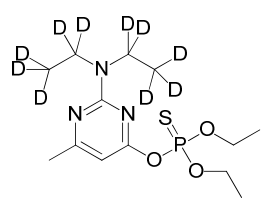




\begin{tabular}{|c|c|c|c|c|}
\hline & Q1 & structure & Q2 & proposed structure \\
\hline Trichlorfon & 257 & & 109 & 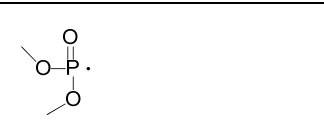 \\
\hline
\end{tabular}

Carbamazepine D10 247

